\title{
Mental Accounts and the Marginal Propensity to Give
}

\author{
David Clingingsmith* \\ Department of Economics \\ Case Western Reserve University
}

June 2019

\begin{abstract}
Neoclassical theory holds that different sources of income are fungible at the margin. In contrast, mental accounting holds that appropriate uses for income vary by source, making them infungible. This study investigates which theory better describes giving at the margin when income may have multiple sources. Dictators accrue differing amounts of 1) earned income from a real-effort task, 2) windfall income, or 3) both. I find that dictators treat marginal earned and windfall income as partially infungible, supporting mental accounting. Dictators who had a single income source gave $14 \%$ of a marginal windfall token and $5 \%$ of a marginal earned token. Strikingly, dictators who had income from two sources were sharply less generous with both, giving only $2 \%$ and $1 \%$, respectively. Multiple accounts enabled greater marginal selfishness. A follow-up experiment shows that two accounts must be qualitatively different, not just multiple in number, to produce this effect.
\end{abstract}

JEL Codes: D64, D63, D83

Keywords: Mental accounts; social preferences; marginal income.

*Email: david.clingingsmith@case.edu. Thanks for helpful comments and suggestions to John List, Dirk Engelmann, Robin Dubin, Silke Forbes, Sue Helper, David Huffman, Roman Sheremeta, Matt Sobel, Justin Sydnor, Mark Votruba, and seminar audiences at IUPUI, the 2013 ESA World Meetings, 2013 Science of Philanthropy Initiative Conference, and The Ohio State University. I also thank Robert Slonim and two anonymous referees for this journal for their guidance in revising the paper. Trevor Allen and Anthony Gatti provided excellent research assistance. 


\section{Introduction}

We are all asked from time to time whether we would like to give money to others. Solicitations arrive by post and e-mail, friends seek sponsorship for charity runs and rides, and retail stores ask if we will donate to a food bank or other charity as we check out. We respond to these requests in part by considering the income at our disposal. Our income come to us from a wide variety of sources, such as wages, bonuses, business profits, welfare benefits, tax refunds, rent, investment returns, gifts, gambling winnings, and so forth.

Neoclassical theory holds that sources of income are fungible. What matters for choice is only the total amount. ${ }^{1}$ By contrast, mental accounting holds that, because individuals view some kinds of spending as more appropriate for some sources of income than others, the sources of income as well as the total matter for choice (Thaler, 1999).

These two theories have contrasting predictions for how changes in income at the margin affect behavior. Neoclassical theory holds that while a marginal increase or decrease in income may affect choice, the source of that marginal change will not matter. Mental accounting holds that if the sources concerned are seen as more or less appropriate for the choice under consideration, then how choice changes will depend on the source of the marginal change in income. In short, neoclassical economics thus holds income to be perfectly fungible at the margin across sources, while mental accounting holds it to be infungible.

While there are many potential sources of income that might be treated as different mental accounts, Thaler (1999) highlighted earned income and windfall income as two sources that tend to be treated differently with respect to consumption. In particular, people tend to splurge on indulgences when they get a marginal increase in windfall income but not earned income. There is suggestive evidence that earnings and windfall might also be infungible where giving to others is

\footnotetext{
${ }^{1}$ Time and liquidity also often figure in a neoclassical model, but I abstract from them here.
} 
concerned: Dictators give less on average if they earn their endowment than if they receive it as a windfall (e.g. Hoffman et al., 1994; Cherry, 2001; Cherry et al., 2002; Cherry and Shogren, 2008; Spraggon and Oxoby, 2009; Cappelen et al., 2013). However, since designs in this dictator game literature measure average giving from one source at a time, they cannot provide the test of fungibility at the margin needed to comprehensively distinguish the mental accounting and neoclassical theories. To do so we need to modify the design so that there is variation in income at the margin from earnings and windfall.

This paper experimentally investigates how the marginal changes in earned income and windfall income affects giving decisions. I recruited 1,022 participants from an online labor market to take on the role of dictator or receiver. Dictators earned income via a real-effort task and/or were given windfalls. They then made a decision about how much of their income to give to receivers.

The experiment answers two primary questions: 1) Do dictators treat earned and windfall income as fungible at the margin, as the neoclassical account would predict, or as infungible, as mental accounting would suggest? 2) Does behavior differ when both income sources are present at the same time than when only one source is present?

Dictators were randomized into treatment cells that induced exogenous variation in both 1) whether and 2) how much income was accrued from earned and windfall sources. Treatment cells are partitioned into two groups that differ in the number of income sources. Dictators get either earned or windfall income in single-source treatments but get both in the two-source treatments. The design insures marginal changes in sources are not correlated with total income (see online appendix).

Pooling the single and two-source treatments, I find that dictators are more generous with marginal windfall than marginal earnings, which is inconsistent with fungibility and supports the mental accounting view. Dictators gave $13 \%$ of a marginal windfall token and $5 \%$ of a marginal 
earned token. An interaction between earned and windfall income is negative and significant, which shows that dictators treat windfall and earned tokens as only partially rather than fully infungible. In other words, the marginal propensity to give from either source falls in the level of the other source, holding total income constant.

Looking at marginal giving in the single- and two-source treatments separately complicates the picture. With only one source present, the marginal propensity to give from an additional token is $14 \%$ for windfall and $5 \%$ for earnings. With both sources present, the margins are $2 \%$ for windfall and $1 \%$ for earnings and are statisitically indistinguishable. The infungibility in the pooled analysis is driven by the extensive margin of number of sources present. A follow-up experiment in which both sources are windfalls does not show this extensive margin effect, suggesting a qualitative difference in sources is necessary for it.

Section 2 describes the design of the experiment and methods of analysis. Section 3 presents the results. In section 4, I discuss the implications of my findings for the neoclassical and mental accounting theories with respect to giving.

\section{Design and Methods}

\subsection{Design}

Participants in the experiment are divided into two roles, dictator and receiver. Dictators first accumulate income. There are two sources of income: earned income $e$, which is based on performance on a real-effort task and windfall income $w$. Total income is $y=w+e$. Dictators are presented with the choice to give some of their total income to a receiver. I will call the amount given $g$ and call the mapping between income and choice $g(w, e)$. The experiment uses variation in $w$ and $e$ to allow for measurement of the marginal effects $g_{w}$ and $g_{e}$ at different values of $(e, w)$.

The experiment used Indian workers in the online labor market Amazon Mechanical Turk (AMT) as subjects. Further details on recruitment are provided in the online appendix. Workers were divided into dictator-receiver pairs for a one-shot game. Participants received a fixed payment of 
\$0.40 for agreeing to take part. I referred to dictators and receivers as role B and role A within the experiment. Dictators accumulate tokens as compensation for completing a task, as a windfall, or both. Tokens were worth $\$ 0.03$ each. After accumulating tokens, dictators are given an opportunity to give to their partner. Dictators know their partners have not been given a chance to accumulate any tokens. Tokens are paid out after the experiment is over. Participants also completed a short demographic survey.

The token-earning activity is a time-limited number-matching task. The number-matching task allowed dictators to earn tokens through exerting effort. In the task, dictators are shown a series of grids containing nine numbers between 1 and 99. Figure 1 shows an example. Each grid contains at least two numbers that sum to 100. Participants solve the grid by clicking check boxes next to two numbers that sum to 100 . Once two check boxes have been clicks, the experiment automatically advances to the next grid.

The task lasts a fixed duration the length of which depends on the treatments discussed below. Participants were awarded tokens based on whether the scored above or below the median for the duration they were assigned. A pilot test established the median for each task duration. No feedback was provided on performance or on the number of grids attempted during the task.

Dictator-receiver pairs were randomly assigned to one of 25 treatments that fall into two groups. The single source group has earned income only and windfall income only treatments, while the two-source group has earned and windfall income treatments. This design allows me to investigate whether giving behavior changes when there are two mental accounts of different sources as opposed to a single account of either source.

The treatments are structured to meet three objectives. The first objective is to create exogenous variation in both earnings and windfall. This is a challenge in the case of earnings, as the skilland effort an individual brings to bear on the task means that their reward $e$ is endogenous. The second goal was to produce variation in $w$ and $e$ that spans the positive orthant between total income levels of 30 and 270 tokens, which allows for the measurement of marginal effects. The third objective is ensuring that the share of expected income from earnings is uncorrelated with total earnings. Section A2 of the online appendix discusses the design of the treatments in detail. 
I use the random assignment of duration, treatment, and windfall level to create instrumental variables for actual earnings and actual windfall. Under the assumption that task duration has an effect on sharing only through its effect on income, expected earnings and windfall are valid instrumental variables for actual earnings.

After accumulating tokens, dictators are given an opportunity to give tokens to their partner. Figure 2 shows how the decision is presented to the dictators in the two-source treatments. Dictators make a single choice involving total income. The bars shown in the figure are initially in the zero position and have to be adjusted to the dictator's choice. A second screen reviewed their choice and asked them to confirm or revise.

AMT workers are difficult to monitor, which may increase the temptation to shirk. To test whether workers were paying close attention, my experiment included a manipulation check.

\subsection{Methods}

I distinguish between the neoclassical and mental accounting theories by testing whether dictators treat marginal earned and windfall income as completely fungible $\left(g_{w}=g_{e}\right.$ and $g_{w w}=$ $\left.g_{w e}=g_{e e}\right)$, completely infungible $\left(g_{w} \neq g_{e}\right.$ and $\left.g_{w e}=0\right)$, or partly infungible $\left(g_{w} \neq g_{e}\right.$ and

$\left.g_{w e} \neq 0\right)$. (Section A1 of the online appendix provides a fuller discussion.)

Equation 1 is a regression of the dictator's choice $g i$ on the windfall income $w i$ and earned income $e_{i}$.

$$
g_{i}=\alpha+\beta_{w} w_{i}+\beta_{e} e_{i}+\beta_{w e}\left(w_{i} \times e_{i}\right)+\varepsilon_{i}
$$

Unobserved variation in sharing is $\varepsilon i$. Fungibility predicts that $\beta_{w e}=0$. In tests of fungibility I also introduce squared terms in $w i$ and $e i$.

If skill at the task has a direct effect on the sharing choice, OLS estimates could be biased. Because the design ensures that there are both above and below median performers at almost every realized $(w, e)$, the bias is likely to be small. Nevertheless, I compute the expected windfall and earned income for each randomly-assigned treatment cell and use them as instruments for $w i$ and $e i$.

In most dictator games, a substantial fraction of participants give zero (Engel, 2011). This 
discontinuity in the amount given suggests modelling the decision of dictators in two steps: 1. whether to give or not (extensive margin), and 2. if giving, how much to give (intensive margin) (BenNer et al., 2004; Erkal, 2011). It is possible that the effects of earnings are different on these two margins, which we will see is in fact the case. I use a Heckman two-step procedure to estimate the marginal propensity to give for givers. Let $p_{i}$ indicate whether a dictator gave at all. The two-step procedure uses an augmented version of equation 1 for $g_{i}$ and a second equation for $p_{i}$.

$$
\begin{aligned}
g_{i} & =\alpha+\beta_{w} w_{i}+\beta_{e} e_{i}+\beta_{w e}\left(w_{i} \times e_{i}\right)+\gamma \lambda\left(x_{i}^{\prime} \widehat{\Theta}\right)+\epsilon_{i} \text { if } p_{i}=1 \\
p_{i} & =\delta+x_{i}^{\prime} \Theta+v_{i} \text { for all } i
\end{aligned}
$$

where $\lambda(\cdot)$ is the Inverse Mills ratio and $x_{i}$ contains treatment cell dummies. The estimated coefficients

$\widehat{\Theta}$ are obtained by probit estimation of equation (3) on the full data. Estimates of $\widehat{\beta_{w}}, \widehat{\beta_{w}}$ and $\widehat{\beta_{w}}$ are obtained by estimating equation 2 by 2SLS on the subset of participants who gave a positive amount.

\section{Results}

A total of 1,636 AMT workers completed in the experiment and passed the manipulation check (pass rate was 76\%; see section A2.3 of the online appendix). There were 1,022 participants in the main experiment and 614 participants in the follow-up experiment. Information on participant characteristics and task performance can be found in section B2.4.

\subsection{Fungibility of earned and windfall income}

We begin the analysis by considering whether dictators treated earned and windfall income as fungible. This analysis pools the single-source and two-source treatments.

Table 1 shows estimates of equation 1. OLS estimates are in column 1 while 2SLS estimates are in column 2. The estimated coefficients are quite similar in size, suggesting that task skill is not an important source of bias in the OLS. I will nevertheless proceed with 2SLS as my preferred estimator since we know the identifying variation was randomly assigned.

The results show us that dictators treat windfall and earned income differently. The propensity to give $13 \%$ of a marginal token is more than twice as large as the $5 \%$ marginal propensity to give from earned tokens (column 2). The difference in marginal propensities is 
statistically significant at $\mathrm{p}=0.01$. This shows that dictators treat the sources of income as infungible, which supports the contention that dictators use mental accounting. The negative and statistically significant interaction between windfall and earned tokens shows us the two sources are partially, rather than completely, infungible. An additional earned token will have a negative effect on the marginal propensity to give windfall, and vice versa. If sources were completely infungible the interaction would have been zero. Note also that since total income is just the sum of earned and windfall, column 2 shows that dictators give approximately $9 \%$ of a marginal increase in total income.

I add squared terms in column 3. If the marginal propensity to give changed at different rates for earned and windfall income, our conclusion of partial infungibility from column 2 could be spurious. The negative coefficients on these terms show that the marginal propensity to give is declining in the number tokens. They also allow me conduct an additional test for fungibility: the equality of second-order derivatives. This test also confirms that dictators treat earned and windfall income infungibly.

I show estimates of the two-step model in column 4. The larger coefficients on windfall and earned tokens reveal that givers are more sensitive to their available resources in their giving than dictators are overall. However, as with dictators overall they exhibit a higher marginal propensity to give out of windfall than earned income $(\mathrm{p}=0.03)$.

\subsection{Marginal propensity to give and the number of sources}

Recall that in some treatments dictators accrued income from one source only (windfall or earned) while in other treatments they accrued income from both sources. Dictators with one source of income are making decisions about a single mental account while those with two sources are deciding about two mental accounts. When there are two accounts, the decision is more complex, which has been associated with increased selfishness (Dana et al., 2007; Hamman et al., 2010; Lazear et al., 2012).

To explore whether the number of sources matters for giving, I interact the coefficients on windfall and earn income with a dummy variable for two source treatments and present estimates 
in Table 2. I also include a dummy for task only treatments. The marginal effects of additional windfall and earned tokens for single and two sources are provided at the bottom of the table. Column 1 shows that when a single source is present, dictators give 0.14 of an additionalwindfall token and 0.05 of an additional earned token. The negative interaction terms with the two source dummy shows that dictators have much lower marginal propensity to give from either source when two are present. When two sources are present, dictators give only 0.02 of an additional windfall token and 0.01 of an additional earned token. The earned estimate is not statistically different from zero and the earned and windfall estimates are not statistically different from each other. Note that while the marginal effects become very small, the dummy for the two-source treatments is a large and statistically significant 5.68 tokens. Average giving is actually similar in the two- and single-source treatments at $19 \%$. The difference between single and two-source treatments is primarily at the intensive margin.

I show estimates for the two-step model in column 2. Givers give 0.21 of a marginal windfall token and 0.11 of a marginal earned token when they have a single source of earnings. The difference of 0.10 tokens is statistically significant with $p<0.01$. When there are two sources generosity falls to 0.08 and 0.06 , respectively, and the difference is not statistically significant.

Both overall and for givers, dictators are more generous with windfall than earned income when making decisions about them as a single source. When making decisions about them jointly, they are less generous overall at the margin but treat earned and windfall income more similarly. The presence of two sources as opposed to one makes the dictators much less sensitive to changes in income in their giving behavior. This difference largely accounts for the partial fungibility $\left(\boldsymbol{s}_{\text {we }}<\right.$ 0) observed in the overall data.

Thus far the analysis has been concerned with giving on the intensive margin of total income. Column 3 shows how the number and source of tokens affect giving on the extensive margin. When there is a single source, additional tokens reduce the likelihood of giving at all. A marginal windfall token reduces the propensity to give by five hundredths of a percent while a marginal earned token reduces it by nine hundredths. With two sources marginal windfall and earned tokens have even stronger effects on giving anything of 11 and 15 hundredths of a percent. Differences between 
coefficients are not statistically significant.

The analysis of Table 2 can be summarized in the following findings.

Finding 1 Dictators give more at the intensive margin windfall than earned income when there is a single source.

Finding 2 Dictators give less at the intensive margin from both windfall and earned income when both sources are present than when only a single source is present.

Finding 3. Dictators give a similar amount at the intensive margin from windfall income and earned income when both sources are present.

\subsection{Two windfall sources}

Windfall and earned income differ in three main ways in the main experiment. First, there is a qualitative difference. Earned income is received as compensation for work while windfall income is received unconditionally. Second, when there are two sources, earned and windfall income are presented as distinct accounts. Third, earned income is accrued first and windfall income second. I investigate the roles played by these differences in a two-windfall follow-up experiment that eliminates the qualitative difference between earned and windfall income.

In the two-windfall experiment, there were two groups of treatments in which dictators either got a single source of windfall or two sources of windfall. When there was a single source, dictators learned about their windfall before completing the demographic survey. When there were two sources, they learned about the first source, took the demographic survey, and then learned about the second source. This spacing in time was designed to emphasize that there were two sources. As with the main experiment, dictators made choices about their total earnings. A total of 198 dictators participated in the two-windfall experiment. Their characteristics are comparable to participants in the main experiment.

I present results on the two-windfall experiment in Table 3. Column 1 shows an OLS estimates of a regression of tokens given on first and second windfall tokens, an interaction between first windfall tokens and the presence of two sources, and a two-source dummy. (There is no endogenous effort in the follow-up experiment so no need for 2SLS.) Note that in this experiment 
the second windfall only occurs when there are two sources. The regression shows dictators give 0.18 of a marginal token from the first windfall and 0.25 of a marginal token from the second windfall. The difference between these margins is not statistically significant. Dictators treat the two wind- falls as fungible.

The interaction between first windfall and two sources is 0.06 and is statistically indistinguishable from zero. This tells us that dictators treated marginal tokens from the first windfall no differently when there were two sources than when there was a single source. Recall that in the main experiment, exposure to two sources lead to a reduction in marginal giving from both sources, while here two sources has no effect on marginal giving. This suggests again that the qualitative nature of the sources, particularly that one is earned income, matters for the effect of multiple accounts on giving.

Column 2 shows the two-step estimates. Givers are also more sensitive to marginal tokens from the second windfall than the first, and their propensity to give from the first source does not change when a second source is added. The same pattern applies to the extensive margin shown in column 3, which, as in the main experiment, show that the marginal propensity to give any tokens falls in the number of tokens acquired.

The two-windfall experiment contributes the following finding to the analysis.

Finding 4 Dictators give less at the margin when there are two-sources only if one of those sources is earned income.

\section{Discussion}

The experimental evidence presented above sheds light on how differences in income sources affect giving behavior. It builds on a longstanding literature on income sources in dictator games (cited in the introduction) by considering marginal rather than average giving and by having endowments composed of two sources.

The design presents dictators with varying amounts of either windfall or earned income (single source treatments) or with varying amounts of both (two source treatment). I find that the marginal willingness to give is 1) higher for windfall than earned income in the single source treatment, 2) 
lower for both windfall and earned income in the two source than the single source treatment, and 3) equal for windfall and earned income in the two source treatment.

When the data from all treatments is pooled, the analysis rejects fungibility of earned and windfall income. This suggests that mental accounting better accounts for the treatment of income sources than the neoclassical model with respect to giving. However, when the treatments are disaggregated, as described in the foregoing paragraph, the picture is more complex. Dictators with both earned and windfall income treat them as fungible, though the presence of both sources substantially lowers marginal generosity relative to when only one is present. One interpretation is that mental accounts are not implicitly present in subjects' minds in advance of the experiment but are created when income is assigned. If only earned income is assigned, there is no windfall account with a balance of zero implicit in the decision process. This qualitative difference matters.

The follow-up experiment shows that the number of sources does not affect marginal giving when all sources are windfall. This implies one source must be earned income, or, more conservatively, that the sources must be qualitatively different for the number of sources to matter for marginal giving. While the mechanism for reduced giving is not clear, these findings are consistent with a literature that shows more complex decision frames tend to reduce giving (e.g. Konow, 2000; Dana et al., 2006, 2007; Haisley and Weber, 2010; Hamman et al., 2010; Lazear et al., 2012).

Despite the additional complexity introduced by fungibility when both sources are present, mental accounting remains a superior framework for explaining the full results since sources continue to matter overall. The neoclassical assumption of fungibility is quite stringent, requiring that only amounts and not sources should matter.

In addition to the experimental literature on giving cited above, my work also contributes to the small empirical literature on mental accounts (Kooreman, 2000; Milkman and Beshears, 2009; Hastings and Shapiro, 2013; Abeler and Marklein, 2017). By showing that qualitatively different income sources are infungible in giving, I provide evidence in favor of a mental accounting approach to income sources in a different domain. 


\section{References}

Abeler, J. and F. Marklein. (2017) Fungibility, Labels, and Consumption. Journal of the European Economic Association, vol. 15 (1) p99-127

Ben-Ner, A., Putterman, L., Kong, F., and Magan, D. (2004). Reciprocity in a two-part dictator game. Journal of Economic Behavior \& Organization, 53(3):333-352.

Cappelen, A. W., Konow, J., Sørensen, E. ., and Tungodden, B. (2013). Just Luck: An Experimental Study of Risk-Taking and Fairness. American Economic Review, 103(4):1398-1413.

Cherry, T. L. (2001). Mental accounting and other-regarding behavior: Evidence from the lab. Journal of Economic Psychology, 22(5):605-615.

Cherry, T. L., Frykblom, P., and Shogren, J. F. (2002). Hardnose the Dictator. American Economic Review, 92(4):1218-1221.

Cherry, T. L. and Shogren, J. F. (2008). Self-interest, sympathy and the origin of endowments. Economics Letters, 101(1):69-72.

Dana, J., Cain, D. M., and Dawes, R. M. (2006). What you don't know won't hurt me: Costly (but quiet) exit in dictator games. Organizational Behavior and Human Decision Processes, 100(2):193-201.

Dana, J., Weber, R. a., and Kuang, J. X. (2007). Exploiting moral wiggle room: experiments demonstrating an illusory preference for fairness. Economic Theory, 33(1):67-80.

Engel, C. (2011). Dictator games: a meta study. Experimental Economics, 14:583-610.

Erkal, N. (2011). Relative earnings and giving in a real-effort experiment. American Economic Review, 101(December):3330-3348.

Hamman, J. R., Loewenstein, G., and Weber, R. A. (2010). Self-Interest through Delegation: An Additional Rationale for the Principal-Agent Relationship. American Economic Review, 100(4):1826-1846.

Hastings, Justine S., and Jesse M. Shapiro. 2013. Fungibility and Consumer Choice: Evidence from Commodity Price Shocks. The Quarterly Journal of Economics 128 (4): 1449-98.

Hoffman, E., McCabe, K., Shachat, K., and Smith, V. (1994). Preferences, Property Rights, and 
Anonymity in Bargaining Games. Games and Economic Behavior, 7(3):346-380.

Konow, J. (2000). Fair shares: Accountability and cognitive dissonance in allocation decisions. The American Economic Review, 90(4):1072-1091.

Kooreman, P. (2000). The Labeling Effect of a Child Benefit System. The American Economic Review, 90(3):571-583.

Lazear, E. P., Malmendier, U., and Weber, R. A. (2012). Sorting in Experiments with Application to Social Preferences. American Economic Journal: Applied Economics, 4(1):136-163.

Milkman, K. L. and Beshears, J. (2009). Mental accounting and small windfalls: Evidence from an online grocer. Journal of Economic Behavior \& Organization, 71(2):384-394.

Spraggon, J. and Oxoby, R. J. (2009). An experimental investigation of endowment source heterogeneity in two-person public good games. Economics Letters, 104(2):102-105.

Thaler, R. H. (1999). Mental Accounting Matters. Journal of Behavioral Decision Making, 206(September 1998):183-206. 
Table 1: Marginal Propensity to Give and Fungibility

(1)

(2)

(3)

(4)

\begin{tabular}{|c|c|c|c|c|}
\hline Windfall Tokens & $\begin{array}{l}0.1283 * * * \\
(0.0240)\end{array}$ & $\begin{array}{l}0.1219 * * * \\
(0.0272)\end{array}$ & $\begin{array}{l}0.1428 * * \\
(0.0595)\end{array}$ & $\begin{array}{l}0.1930 * * * \\
(0.0339)\end{array}$ \\
\hline Earned Tokens & $\begin{array}{l}0.0534 * * * \\
(0.0164)\end{array}$ & $\begin{array}{l}0.0627 * * * \\
(0.0137)\end{array}$ & $\begin{array}{l}0.1710 * * * \\
(0.0592)\end{array}$ & $\begin{array}{l}0.1371 * * * \\
(0.0181)\end{array}$ \\
\hline Earned $\times$ Windfall & $\begin{array}{l}-0.0011 * * * \\
(0.0003)\end{array}$ & $\begin{array}{l}-0.0011 * * * \\
(0.0003)\end{array}$ & $\begin{array}{l}-0.0015^{* * *} \\
(0.0004)\end{array}$ & $\begin{array}{l}-0.0014 * * * \\
(0.0004)\end{array}$ \\
\hline Windfall Tokens ${ }^{2}$ & & & $\begin{array}{l}-0.0000 \\
(0.0002)\end{array}$ & \\
\hline Earned Tokens ${ }^{2}$ & & & $\begin{array}{l}-0.0004 * * \\
(0.0002)\end{array}$ & \\
\hline Inverse Mills Ratio & & & & $\begin{array}{l}1.2455 \\
(3.0303)\end{array}$ \\
\hline Constant & $\begin{array}{l}4.5193 * * * \\
(0.9863)\end{array}$ & $\begin{array}{l}4.4820 * * * \\
(0.9112)\end{array}$ & $\begin{array}{l}2.3608 \\
(1.8898)\end{array}$ & $\begin{array}{l}3.6428 * * \\
(1.4476)\end{array}$ \\
\hline Adjusted $R^{2}$ & 0.121 & 0.120 & 0.130 & 0.274 \\
\hline $\mathrm{N}$ & 500 & 500 & 500 & 366 \\
\hline $\begin{array}{l}\text { Estimation } \\
H_{0}: \text { Equal } 2^{\text {nd }} \text {-order derivatives }\end{array}$ & OLS & 2SLS & $\begin{array}{l}2 \text { SLS } \\
<0.01\end{array}$ & 2-Step \\
\hline
\end{tabular}

Notes: 2SLS regressions use expected earned and windfall tokens as instruments. Standard errors clustered by treatment cell. 
Table 2: Propensity to Give By Number of Sources

Number of Tokens

(1)

(2)

Any Tokens

(3)

\begin{tabular}{|c|c|c|c|}
\hline Estimation & 2SLS & 2-Step & 2SLS \\
\hline \multirow[t]{2}{*}{ Windfall Tokens } & $0.1432 * * *$ & $0.2143 * * *$ & $-0.0005 * *$ \\
\hline & $(0.025)$ & $(0.032)$ & $(0.000)$ \\
\hline \multirow[t]{2}{*}{ Earned Tokens } & $0.0454 * * *$ & $0.1140 * * *$ & $-0.0009 * * *$ \\
\hline & $(0.006)$ & $(0.009)$ & $(0.000)$ \\
\hline \multirow[t]{2}{*}{ Windfall $\times$ Two Sources } & $-0.1237 * * *$ & $-0.1363 * * *$ & -0.0006 \\
\hline & $(0.028)$ & $(0.041)$ & $(0.000)$ \\
\hline \multirow[t]{2}{*}{ Earned $\times$ Two Sources } & $-0.0336^{* *}$ & $-0.0549 * *$ & -0.0007 \\
\hline & $(0.013)$ & $(0.023)$ & $(0.001)$ \\
\hline \multirow[t]{2}{*}{ Two Sources } & $5.6790 * * *$ & $6.7675 * * *$ & 0.0213 \\
\hline & $(1.209)$ & $(1.615)$ & $(0.031)$ \\
\hline \multirow[t]{2}{*}{ Task Only } & $3.8963 * *$ & $4.2324 * * *$ & 0.0025 \\
\hline & $(1.570)$ & $(1.631)$ & $(0.081)$ \\
\hline \multirow[t]{2}{*}{ Inverse Mills’ Ratio } & & 1.7773 & \\
\hline & & $(2.829)$ & \\
\hline \multirow[t]{2}{*}{ Constant } & $2.0775 * *$ & 0.8662 & $0.7914 * * *$ \\
\hline & $(1.022)$ & $(1.717)$ & $(0.018)$ \\
\hline Adjusted $R^{2}$ & 0.129 & 0.285 & 0.037 \\
\hline $\mathrm{N}$ & 500 & 366 & 500 \\
\hline \multicolumn{4}{|l|}{ Marginal Propensity to Give } \\
\hline Windfall Tokens, Single Source & $0.1432 * * *$ & $0.2143 * * *$ & $-0.0005 * *$ \\
\hline Earned Tokens, Single Source & $0.0454 * * *$ & $0.1140 * * *$ & $-0.0009 * * *$ \\
\hline Windfall Tokens, Two Sources & $0.0195^{*}$ & $0.0781 * * *$ & $-0.0011 * * *$ \\
\hline Earned Tokens, Two Sources & 0.0118 & $0.0591 * *$ & $-0.0015^{* * *}$ \\
\hline
\end{tabular}

Notes: 2SLS regressions use expected earned and expected windfall tokens as instruments. The first step equation in the two-step estimation uses treatment cell dummies to predict giving. Standard errors are clustered by treatment cell. 
Table 3: Marginal Propensity to Give from Two Windfalls

\begin{tabular}{|c|c|c|c|}
\hline \multirow[b]{3}{*}{ Estimation } & \multicolumn{2}{|c|}{ Number of Tokens } & \multirow{3}{*}{$\begin{array}{l}\text { Any Tokens } \\
\text { OLS }^{(3)}\end{array}$} \\
\hline & $(1)$ & $(2)$ & \\
\hline & OLS & Two-Step & \\
\hline First Windfall Tokens & $\begin{array}{l}0.1815 * * * \\
(0.016)\end{array}$ & $\begin{array}{l}0.3034 * * * \\
(0.026)\end{array}$ & $\begin{array}{l}-0.0055^{* * *} \\
(0.001)\end{array}$ \\
\hline Second Windfall Tokens & $\begin{array}{l}0.2537 * * * \\
(0.067)\end{array}$ & $\begin{array}{l}0.3012 * * * \\
(0.073)\end{array}$ & $\begin{array}{l}-0.0008 \\
(0.002)\end{array}$ \\
\hline First Windfall $\times$ Two Sources & $\begin{array}{l}0.0577 \\
(0.093)\end{array}$ & $\begin{array}{l}-0.0300 \\
(0.125)\end{array}$ & $\begin{array}{l}0.0060 * * \\
(0.002)\end{array}$ \\
\hline Two Sources & $\begin{array}{l}-1.6171 \\
(2.605)\end{array}$ & $\begin{array}{l}0.6224 \\
(3.219)\end{array}$ & $\begin{array}{l}-0.0684 \\
(0.095)\end{array}$ \\
\hline Inverse Mills' Ratio & & $\begin{array}{l}4.3984 \\
(2.859)\end{array}$ & \\
\hline Constant & $\begin{array}{l}0.9545^{*} \\
(0.454)\end{array}$ & $\begin{array}{l}-2.2561 * * * \\
(0.763)\end{array}$ & $\begin{array}{l}0.9193 * * * \\
(0.036)\end{array}$ \\
\hline Adjusted R-squared & 0.051 & 0.101 & 0.009 \\
\hline $\mathrm{N}$ & 198 & 149 & 198 \\
\hline Marginal Propensity to Give & & & \\
\hline First Windfall Tokens, Single Source & $0.1815 * * *$ & $0.3034 * * *$ & $-0.0055^{* * *}$ \\
\hline First Windfall Tokens, Two Sources & $0.2392 * *$ & $0.2734 * *$ & 0.0056 \\
\hline Second Windfall Tokens, Two Sources & $0.2537 * * *$ & $0.3012 * * *$ & -0.008 \\
\hline
\end{tabular}

Notes: The first step equation in the two-step estimation uses treatment cell dummies to predict giving. The first step equation in the two-step estimation uses treatment cell dummies to predict giving. Standard errors are clustered by treatment cell. 
Figure 1: Number-Matching Task

Select two numbers that sum to 100.

$\begin{array}{lll}\square 21 & \square 24 & \square 10 \\ \square 55 & \square 76 & \square 17 \\ \square 27 & \square 7 & \square 74\end{array}$

Figure 2: Dictator's Choice

Your account had 10 tokens to start. You earned 20 from the number-matching task. Your Total: 30

Please decide how many of your 30 tokens you wish to give to your partner and how many you wish to keep for yourself.

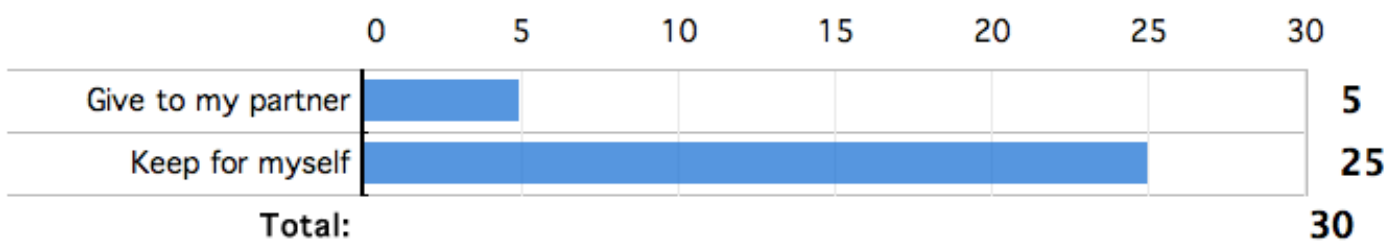

